\title{
Dilema e desafios postos para a sociedade brasileira
}

PLINIO ARRUDA SAMPAIO

\section{Dilema}

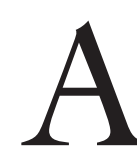

PALAVRA dilema refere-se a situações que colocam para um sujeito qualquer a necessidade de escolher entre alternativas igualmente difíceis e penosas. De acordo com esse conceito, a sociedade brasileira, enquanto sujeito histórico, encontra-se rigorosamente diante de um dilema. As mudanças econômicas e políticas ocorridas, em âmbito planetário, nestas duas últimas décadas, obrigam-na a escolher entre duas alternativas igualmente difíceis e de elevado custo social.

O debate sobre os fatores que conduziram o país a essa situação provoca, como é natural, muita controvérsia, mas todos, na direita e na esquerda, concordam em um ponto: o fator determinante da situação em que nos encontramos foi a inviabilização do modelo econômico que vinha sendo implantado desde as primeiras décadas do século XX, em razão das mudanças ocorridas no sistema capitalista e na ordem política internacional, nas décadas finais daquele século.

Como as possibilidades de integração social e territorial do país dependiam do dinamismo do modelo econômico, a inviabilização deste acarretou a anulação dos mecanismos que possibilitariam o avanço na construção do Estado. Um avanço, convém ressaltar, ambíguo e vacilante, pois se baseava em combinações de atraso-moderno, inclusão-exclusão, concentração de renda-incorporação de massas, elitismo político-ampliação da participação popular - que impunham enormes sacrifícios à maioria da população e tornavam a nação extremamente vulnerável aos movimentos do capital internacional.

"O que permitia aos brasileiros conviver com as gritantes injustiças sociais era o intenso dinamismo da economia. Muitos observadores (inseridos nos segmentos sociais privilegiados, evidentemente) descobriram nesse dinamismo uma fonte de legitimidade para um sistema de poder que gerava tantas injustiças” (Furtado, 1992: 12). 


\section{A opção da elite divigente}

Colocada diante do dilema, a elite dirigente - depois das muitas idas e vindas que marcaram o curso da política do país desde a metade dos anos 70 até o final da década de 80 - desistiu completamente de dar prosseguimento ao projeto de construção do seu Estado-nação. Ela, que vinha se preparando para isto desde os tempos da ditadura militar.

"Os estratos burgueses aprenderam a mudar a qualidade das suas percepções e explicações do mundo, procurando ajustar-se a 'avaliações pragmáticas', que representam o subdesenvolvimento como um 'fato natural' autocorrigível e estabelecem como ideal básico o princípio, irradiado dos Estados Unidos, do 'desenvolvimento com segurança'. Dava-se assim o último salto na limpeza do sótão. A burguesia brasileira encontrava novos elos de 'modernização', descartando-se de suas quinquilharias históricas libertárias, de origem européia, substituídas por convicções bem mais prosaicas, mas que ajustavam seus papéis à 'unidade do hemisfério', à 'interdependência das nações democráticas' e à 'defesa da civilização ocidental"” (Fernandes, 1976: 314).

Acuada entre a necessidade de enfrentar as forças dominantes no sistema capitalista para prosseguir o processo de construção do seu Estado ou renunciar a ele, a elite ficou sem capacidade de reação e acabou tendo de aceitar as imposições dos núcleos centrais do sistema econômico e político da ordem capitalista mundial. Deixou de lado qualquer veleidade de autonomia, passando a buscar desesperadamente alguma forma de inserção no mercado internacional. Para tanto, não teve pejo de alienar parcela importante do patrimônio nacional, de permitir a desnacionalização da indústria do país, de abrir o mercado brasileiro à predação dos capitais especulativos, e de assistir, indiferente, ao empobrecimento do povo e ao agravamento da situação social.

A expectativa da elite é que, "fazendo a lição de casa" passada pelos organismos do Consenso de Washington, os capitais estrangeiros afluam ao país e dinamizem a economia estagnada há duas décadas, criando assim condições para atenuar a situação social e para re-legitimar o seu domínio no contexto de uma democracia restrita.

Esta expectativa não tem fundamento. Como explicou Celso Furtado (1992: 13), "Na lógica da ordem econômica internacional emergente parece ser relativamente modesta a taxa de crescimento que corresponda ao Brasil. Sendo assim, o processo de formação de um sistema econômico já não se inscreve naturalmente em nosso destino nacional". 
A evolução econômica destes 10 anos só fez confirmar essa previsão. Ao renunciar ao projeto nacional, a elite dirigente renunciou igualmente a desempenhar qualquer função civilizatória no obcecado em manter os seus privilégios a qualquer preço ... país. Transformou-se em um segmento parasitário, obcecado em manter o seu dinheiro e os seus privilégios a qualquer preço, como o comprova a onda de corrupção que tem acompanhado a desnacionalização da economia, o desmantelamento do Estado e a perda da autoestima do povo.

A guerra de todos contra todos, hoje aberta e declarada em todo o país, ameaça desembocar em um longo período de caos e barbárie ou na inevitabilidade de formas autoritárias de controle da insatisfação popular.

A primeira alternativa que o dilema brasileiro coloca para a nossa sociedade está portanto cheia de dificuldades e sofrimentos.

\section{Falso e verdadeiro dilema}

As análises da situação brasileira, feitas com o propósito de racionalizar os interesses da elite dirigente, concluem invariavelmente pela existência de duas alternativas abertas para o país: inserção do Brasil na ordem mundial emergente ou barbárie.

Os ideólogos da elite afirmam que esta fez a opção "realista" pela primeira alternativa.

Esta forma de apresentar o dilema brasileiro não corresponde à realidade. Fazer crer na possibilidade de inserção não-subordinada na ordem mundial que se está construindo com base no Consenso de Washington é uma falácia. Tal alternativa não existe.

O novo ordenamento do sistema capitalista provoca uma reformulação da divisão internacional do trabalho prevalecente durante a etapa de expansão do capitalismo industrial. De acordo com os parâmetros fixados pelas forças que comandam a transição do capitalismo industrial ao capitalismo globalizado, as economias periféricas devem se especializar na produção daqueles bens e serviços em relação aos quais apresentam "vantagens comparativas”. Ora, essa re-especialização é incompatível com a independência econômica porque agrava limitações que impediram, no passado, o desenvolvimento dos países então periféricos: dependência exagerada das exportações; dificuldade para a introdução de tecnologia moderna na economia; crises cambiais. As crises cambiais de 1997-1998, que atingiram duramente 
os países asiáticos e latino-americanos são um claro sinal do que significa especialização no mundo globalizado. Por isso, a inserção na ordem mundial, nos termos do Consenso de Washington, será sempre subordinada, dê-se a ela o nome que se der.

Poder-se-ia opor a este raciocínio a objeção de que a elite dominante brasileira não optaria por uma inserção subordinada, porque tal alternativa contradiz seus próprios interesses, uma vez que a coloca em posição subalterna diante das forças que passarão a controlar a economia nacional. A contradição é aparente, porque a opção permite à elite realizar seus dois grandes objetivos: manter internamente a hegemonia do poder político; e modernizar seus padrões de consumo. A subordinação a comandos externos, portanto, não a perturba, ainda que represente a manutenção do país em estado de subdesenvolvimento, o aumento do hiato entre o nosso país e as nações tecnologicamente mais adiantadas e o agravamento do "apartheid social".

A alternativa da elite é que tem conduzido o país à barbárie.

Os sinais disto já não podem ser ocultados. Basta ver a violência da luta pela terra, que cobra mortos e feridos praticamente a cada dia; o aumento explosivo tanto da criminalidade difusa quanto do crime organizado nas cidades; a multiplicação das situações de duplo poder nas periferias dos grandes centros; a incidência da morte violenta como a principal causa mortis dos jovens entre 16 e 25 anos; a proliferação das favelas e dos "sem teto"; o reaparecimento de enfermidades decorrentes da falta de saneamento e de higiene, como a dengue e a cólera; a extraordinária deterioração do ensino público.

Todos esses males sociais são o resultado do "modelo de inserção subordinada", pois são conseqüência direta do desemprego; da propagação da cultura consumista; da concentração de renda nos estratos superiores da pirâmide social; da "austeridade fiscal", que retira recursos dos serviços públicos para garantir o pagamento da dívida interna e externa do Estado.

Nesse contexto, a proclamada "inserção não-subordinada", mencionada pelos ideólogos da elite, não passa de uma expressão usada apenas para "salvar a face", ou então para iludir os grupos sociais que ainda alimentam a esperança de construir uma nação autônoma sem pagar os preços que isto requer.

Para os que não querem se deixar iludir, há uma outra alternativa, que não representa a barbárie e que pode salvar os valores da civilização - a retomada da construção nacional. 
Optando pela construção da nação, o país não poderá fugir das dificuldades e do sofrimento, porque disso não escapa a sociedade que vive um dilema, mas caminhará na direção de uma nação civilizada, livre dos males sociais que hoje o caracterizam.

\section{A opção pelo projeto de construção nacional}

Como a construção nacional foi sempre um processo ambíguo e contraditório, convém esclarecer inicialmente que, na atual conjuntura, a nação cuja construção pode ser retomada não consiste, de modo algum, na reprodução do modelo econômico e do modelo político do passado, quando o processo era comandado pela atual elite dirigente.

Para que represente de fato um avanço na longa transição do Brasilcolônia ao Brasil-nação, a construção da nação tem de ter outro fundamento e outra direção, que exigem outra estrutura de poder e outro programa político.

Em um estudo sobre os "Impasses da Formação Nacional”, Plinio Sampaio Jr. tratou dessa questão sob um enfoque novo. Vale, por isso, alongar-se um pouco na transcrição do seu raciocínio:

"Antes de condicionar a emergência de nossa nacionalidade ao aparecimento de uma nova raça oriunda da mestiçagem, ao controle de um vasto território rico em recursos naturais e às ilimitadas potencialidades de sua economia, à estruturação de um aparelho de Estado capaz de impor a autoridade da ordem e a descabidos sonhos ufanistas de um hipotético Brasilpotência - concepções chauvinistas que ocultam a natureza hierárquica e autoritária de nossa formação social -, o pensamento democrático entende a afirmação da nacionalidade como a necessária cristalização de uma sociedade homogênea, portadora dos valores humanistas da civilização ocidental, baseada em nexos morais entre as classes sociais e na existência de laços orgânicos entre as diferentes regiões do país.

Nesta abordagem, o espaço nacional não passa de um instrumento para proteger a coletividade dos efeitos destrutivos das transformações que se irradiam desde o centro do sistema capitalista mundial e para planejar a internalização das estruturas e dos dinamismos da civilização ocidental de modo condizente tanto com o aumento progressivo do grau de autonomia e criatividade da sociedade quanto com a elevação da riqueza e do bemestar da totalidade do povo. Pensada como um centro de poder que condensa a vontade política da coletividade, a fórmula nacional é aqui - única e exclusivamente - um meio de sociedades que vivem sobre determinadas pelo 
campo de força do sistema capitalista mundial controlarem o seu tempo histórico. Trata-se, portanto, de um instrumento, historicamente determinado, que deveria ser ultrapassado por formas superiores de organização social e política, de alcance supranacional, assim que o contexto histórico mundial o permitisse. Isto é, assim que a ordem mundial deixasse de estar sob o domínio da lógica da concorrência intercapitalista e das rivalidades interestatais do imperialismo" (Sampaio Jr., 1999: 46).

Alguns analistas do caso brasileiro entendem que não é mais possível retomar a construção nacional. Segundo eles, a globalização da economia enfraqueceu de tal maneira o poder regulador dos Estados, que estes não têm mais como controlar seu espaço econômico. Ademais, o fim da bipolaridade do sistema político internacional estreitou tanto as margens da barganha política dos países subdesenvolvidos, que estes não podem mais usar este recurso para se afirmar como nações, no sentido que esta palavra adquiriu nos séculos XIX e XX.

Este argumento pode ser assim resumido: constitui uma verdadeira ingenuidade a tentativa de fortalecer o edifício nacional que começou torto e ficou incompleto, exatamente na hora em que, em todo o mundo, a forma política do Estado-nação está sendo minada por dentro e por fora. Por dentro, em razão das secessões étnicas, regionais e religiosas que corroem o cerne mesmo da nação - o sentimento de identidade; por fora, em razão do poder crescente das organizações supranacionais que lhe restringe a soberania.

Para refutar esse raciocínio falacioso basta lembrar o nacionalismo exacerbado das sete nações que, à revelia da ONU, conformam o "comitê diretor" da política mundial nos dias de hoje. Alguns exemplos recentes bastam para demonstrar que, para essas nações, o Estado-nação não foi "historicamente ultrapassado". A Corte Penal Internacional, criada pela ONU, não conseguiu se instalar até hoje porque os Estados Unidos recusam-se a admitir que sua jurisdição abranja os cidadãos norte-americanos. A França bloqueou faz pouco tempo a aprovação do AMI (Acordo Multilateral de Investimentos) sob a alegação de que o mesmo feria a soberania francesa. Que dizer então do conflito entre os Estados Unidos e os países europeus a respeito da liberalização do comércio agrícola internacional?

Não há como falar em obsolescência do Estado-nação. Que outra forma de poder político poderemos construir, nós os subdesenvolvidos, para resistir a esses nacionalismos agressivos e à dura realidade de uma divisão internacional do trabalho, que impede os países subdesenvolvidos de organizar sistemas produtivos aptos a eliminar a miséria absoluta que atinge grande parte de suas populações? 
A escolha real que está posta para a nossa sociedade não é, pois, como querem os ideólogos da elite, a de se inserir (inevitavelmente de forma subordinada) na ordem internacional emergente ou projetar-se na barbárie na tentativa impossível de completar uma forma anacrônica de organização do poder político. A escolha real consiste em inserir-se subordinadamente nessa ordem ou lançar-se na empresa histórica de completar a construção da nação, a fim de fugir ao destino inglório da re-colonização.

Não se deve entender que este caminho represente uma opção por isolar-se da comunidade internacional. Trata-se apenas de uma modalidade nova de relacionamento com essa comunidade, a fim de que a absorção de tecnologia gerada em outras partes do planeta se faça em função dos interesses do conjunto da população e da soberania do país e não, como agora, em função exclusivamente da modernização dos padrões de consumo.

A sociedade brasileira tem condições de dar esse passo, primeiro porque o sentimento nacional já penetrou consideravelmente em todas as ca-

a sociedade brasileira

tem condições

de dar esse passo ... madas da população e em várias instituições estratégicas para a formação de um Estado nacional; em segundo lugar porque o desenvolvimento das forças produtivas já atingiu em nosso país um patamar suficiente para produzir os bens e serviços requeridos para assegurar um padrão de vida adequado a todos e, finalmente, porque, como disse Celso Furtado (1992: 12, “Em poucas áreas do mundo a relação homem/recursos naturais, inclusive solo e água para agricultura, é tão favorável como entre nós”.

Não há dúvida, entretanto, de que a construção nacional constitui uma via de dificuldades e penas, porque, para retomar esse processo são indispensáveis decisões que afetam interesses muito poderosos.

A primeira dessas decisões diz respeito à redistribuição da riqueza e da renda, hoje extremamente concentradas nos patamares superiores da pirâmide social. Sem tal redistribuição, será impossível transformar o mercado interno em núcleo dinamizador da economia, e, sem uma economia dinâmica, não serão produzidos, em qualidade e quantidade, bens e serviços indispensáveis ao atendimento das necessidades básicas de toda a população.

Não há, contudo, que confundir o atendimento das necessidades básicas da população com o consumismo característico dos países capitalistas industrializados. Nossa economia não dispõe de recursos para proporcionar esse padrão de consumo a 170 milhões de habitantes e mesmo que dispu- 
sesse, não haveria como evitar uma catastrófica agressão ao meio ambiente, uma vez que a característica desse tipo de consumo é o extraordinário desperdício. Por isso, quando se fala em atender às necessidades básicas da população, está-se falando de um consumo frugal, compatível com o objetivo de satisfazer todos os habitantes sem comprometer o meio ambiente. Um consumo frugal, mas nem por isso impeditivo de proporcionar a todos, como atributo da cidadania plena, um padrão de vida que ponha ao alcance dos brasileiros os meios de acesso ao conforto e aos avanços intelectuais, morais e espirituais da civilização.

O mercado interno dinâmico constitui uma condição indispensável para dar estabilidade à economia. Como se assinalou anteriormente, quando o dinamismo da economia depende da demanda externa, aumenta sua vulnerabilidade às flutuações de preços determinadas por movimentos fora do controle dos centros internos de decisão.

A segunda decisão crucial a ser tomada para reativar o processo de construção nacional refere-se à ruptura dos laços de dependência externa. A dependência subordina o processo de acumulação de capital ao controle de empresas que visam exclusivamente o lucro e, conseqüentemente, dirigem seus investimentos para os setores que mais podem proporcioná-lo. Em conseqüência, enquanto esse controle não for suprimido, será impossível canalizar o excedente econômico para a ampliação da capacidade produtiva daqueles bens e serviços necessários ao atendimento das necessidades básicas de toda a população.

"Efetivamente, o nosso desenvolvimento econômico, enquadrado no sistema imperialista - e é isso que se propõe com o apelo ao concurso de empreendimentos imperialistas, e que de fato se está no momento realizando no Brasil - se pautará necessariamente pelos interesses dos trustes aqui instalados que se farão, como já acontece e será cada vez mais o caso, o elemento principal e fator decisivo da nossa economia. São os trustes que fixarão as normas, o ritmo e os limites do desenvolvimento, para eles naturalmente determinados pelo montante dos lucros que a economia brasileira é capaz de proporcionar. E que limites são esses? Encontramo-los na margem dos saldos financeiros que o Brasil oferece nas suas contas externas, a saber, aqueles que resultam do nosso intercâmbio com o exterior.

De fato, o lucro auferido pelos empreendimentos imperialistas no Brasil somente se podem liquidar (e somente então constituirão verdadeiros lucros) com os saldos do nosso comercio exterior, uma vez que é da exportação que provêm nossos recursos normais em moeda internacional. Descontada a parte desses recursos que se destina a pagar as importações, é do 
saldo restante, e somente deles, que poderá sair o lucro dos empreendimentos aqui instalados pelos trustes. Na base do previsível para esse saldo, portanto, fixarão os trustes o limite de suas atividades; e portanto, em conseqüência, o do desenvolvimento brasileiro que no sistema vigente é por eles enquadrado" (Prado Jr., 1987: 88).

A longa citação de um texto escrito há 30 anos ajuda a entender porque o desenvolvimento precisa basear-se nos recursos do país e fornece ademais um elemento para compreender porque nosso país não conseguirá jamais se libertar do endividamento externo, enquanto sua economia depender dos capitais estrangeiros.

O desenvolvimento do espaço econômico nacional supõe a existência de um Estado capaz de controlar a introdução no país dos avanços das técnicas produtivas. Se esse controle já era difícil na etapa anterior, em que o capital transnacional se deslocava para a periferia, a fim de disputar os mercados desses países, mais difícil é agora, quando o capitalismo passa, em ritmo vertiginoso, a concentrar nas economias centrais, tanto o capital quanto a inovação tecnológica.

A simples menção das medidas que se necessitará tomar para cumprir essas duas pré-condições da retomada do processo de construção nacional deixa ver quão difícil e penoso será ele.

A extraordinária resistência da elite à realização de um arremedo de reforma agrária indica quão acirrada será a luta para realizar uma redistribuição da riqueza e da renda que promova, efetivamente e em prazo relativamente curto, a homogeneização da sociedade brasileira. É ilusório imaginar que isto possa ser conseguido sem enfrentar o boicote de empresários, a ofensiva da mídia, a resistência difusa de todos quantos terão de perder privilégios para que o país possa progredir.

As reações dos núcleos centrais do sistema capitalista e das grandes potências mundiais a uma política econômica voltada para a retomada da construção nacional são também bastante previsíveis: fechamento das linhas de financiamento; obstáculos às exportações; fuga de capitais; recusa de transferência de tecnologia. Uma política de ruptura com a dependência significa o fim dos privilégios hoje concedidos às firmas transnacionais, o que provocará, sem sombra de dúvida, ferrenha reação. Tendo em vista o alarme que o chamado "efeito dominó" causa nas potências dominantes, não se deve descartar que às pressões econômicas se acrescentem pressões diplomáticas e até militares - episódios usuais no tempo da Pax Britannica e da gun boat diplomacy, os quais continuam ocorrendo, sob novas formas, no Iraque, na Iugoslávia, na Líbia, no Sudão e em Cuba. 
Obviamente, as represálias causarão dificuldades e sofrimentos para a população brasileira. Mas, embora alguns não acreditem, temos todas as condições para resistir.

Com essa visão realista do presente e do futuro, é possível apontar os desafios decorrentes da alternativa que, como ensinou Caio Prado Jr., corresponde ao sentido mais profundo da nossa evolução histórica: a transição do Brasil-colônia ao Brasil-nação.

“É assim que se há de abordar a realidade brasileira atual, o que leva a considerá-la como situação transitória entre, de um lado, o passado colonial e o momento em que o Brasil ingressa na história como área geográfica ocupada e colonizada com o objetivo precípuo de extrair dessa área produtos destinados ao abastecimento do comércio e mercado europeus; de outro lado o futuro, já hoje bem próximo, em que essa mesma área e seu povoamento, afinal nacionalmente estruturados, comportarão uma organização e sistema econômico voltados essencialmente e fundamentalmente para a satisfação das necessidades dessa mesma população que a ocupa, e capazes de assegurar a essa população um nível e plano de existência consentâneos com os padrões da civilização e cultura de que participamos" (Prado Jr., 1987: 88).

\section{Desafios}

Ao examinar os desafios que a situação atual coloca para a sociedade brasileira, é preciso, preliminarmente, determinar quem está sendo desafiado. Como a elite brasileira renunciou ao projeto de construção nacional, o desafio logicamente não se dirige a ela e sim a um conjunto formado por segmentos sociais bastante diversos, mas que têm em comum o fato de serem todos eles prejudicados pelo "modelo de inserção subordinada".

Dada a dificuldade de aplicar à nossa sociedade atual as clássicas definições de classes sociais, pode-se chamar esse conjunto de "classes populares".

\section{Pensar o Brasil}

\section{e o mundo fora dos parâmetros estabelecidos}

O primeiro desafio posto para as classes populares consiste em pensar o Brasil e o mundo com liberdade. Quem o diz é Celso Furtado (1992: 76): "O desafio que se coloca no umbral do século XXI é nada menos que mudar o curso da civilização, deslocar o seu eixo da lógica dos meios a serviço da acumulação, num curto horizonte de tempo, para uma lógica dos fins em função do bem estar social, do exercício da liberdade e da cooperação entre os povos". 
Não é nada fácil pensar fora dos parâmetros da ortodoxia estabelecida pelas instituições que racionalizam a dominação da elite, aí compreendidas a academia, a mídia, a administração pública. Essa ortodoxia penetrou tanto na cultura e na consciência do povo que já adquiriu o estatuto de verdadeiro "senso comum". Para pensar fora dos seus parâmetros, é preciso que as classes populares, mediante suas organizações, seus movimentos e suas lutas, consigam criar foros de reflexão autônomos e formar intelectuais orgânicos, aptos, não só a formular novos diagnósticos e estratégias para superar o subdesenvolvimento, como a assumir corajosamente a luta ideológica destinada a desfazer o "senso comum" criado pelos dominantes.

Só no bojo de um processo com esses objetivos e essas características, as classes populares terão condições de expandir a consciência da dominação a que estão submetidas. Desta consciência, e só dela, é que poderão surgir os elementos de força requeridos para derrotar a elite, assumir o poder e executar o seu programa de transformação social.

O desafio abrange ainda a capacidade de gerar movimentos, instituições, lideranças e partidos aptos a organizar e dirigir a luta política, conseguir a unidade do povo e dar os golpes decisivos na dominação da elite dirigente. A dificuldade maior para atingir esses objetivos consiste em recusar o eleitoralismo e combinar adequadamente a atuação política dentro dos marcos da institucionalidade estabelecida pela elite com a pressão direta de massas por suas reivindicações e pelo aprofundamento da democracia em todos os planos da nossa sociedade.

Florestan Fernandes sintetizou as tarefas dessas organizações das classes populares em três breves consignas, que podem ser assim resumidas: não se deixar co-optar pela ordem e pelo pensamento racionalizador dos interesses da elite; não se deixar aniquilar em movimentos temerários e aventureiristas; desenvolver a habilidade de conseguir vitórias para o povo. Toda uma ética está contida nessas recomendações. Essa ética exige que as vanguardas das classes populares não escondam a realidade do povo e nem rebaixem os objetivos da revolução popular.

\section{Derrotar a mentalidade colonizada da elite e dos segmentos contaminados por ela}

O segundo desafio é correlato com o anterior: trata-se de derrotar a mentalidade colonizada que impera entre os segmentos superiores da pirâmide social e contamina as camadas populares. A mentalidade colonizada provoca o sentimento de inferioridade, a idéia enganosa de que não temos condições de vencer o subdesenvolvimento sem a ajuda do pensamento 
mais avançado, formulado no estrangeiro; sem os recursos técnicos concentrados nesses países; e sem as virtudes morais e a capacidade psicológica desses "seres superiores". Enquanto esse tipo de consciência for dominante, não só na elite, mas mesmo entre as classes populares, será impossível "pensar fora dos parâmetros estabelecidos" e superar outro grande obstáculo ao nosso desenvolvimento: o consumismo.

O consumismo consiste em uma atitude mental que tomou conta das classes situadas nos patamares superiores da pirâmide social e que a mídia transformou em ideal de vida e disseminou até entre aqueles que jamais terão renda capaz de sustentar um nível elevado de consumo de bens e serviços. O consumismo é a outra face da mentalidade colonizada, pois deriva do fascínio com os padrões de consumo típicos dos extratos médios e superiores dos países desenvolvidos. Tais padrões, difundidos pelo cinema e pela televisão, constituem hoje, para as multidões, a expressão maior da felicidade humana.

Enquanto o sentimento de inferioridade e o consumismo desenfreado povoarem o consciente e o subconsciente das pessoas, inclusive das que integram as classes populares, será impossível organizar um sistema de produção de conhecimentos científicos e tecnológicos adaptados às nossas necessidades e às nossas possibilidades, bem como usar esses conhecimentos para embasar uma organização econômica apta a fornecer os bens e serviços requeridos para propiciar um padrão de consumo adequado a toda a população e para garantir a soberania da nação.

\section{Conquistar o poder político e montar um Estado eficaz}

O terceiro desafio dirige-se aos movimentos e, mais especialmente, aos partidos que representam os interesses e visões de mundo das classes populares. Trata-se de conquistar o poder do Estado, transformando-o em um instrumento de democracia, de desenvolvimento econômico e de promoção da eqüidade social.

A esse Estado caberá a tarefa de proporcionar terra e meios de desenvolvimento à população rural; trabalho produtivo, remuneração adequada; moradia digna aos habitantes da cidade: terra, trabalho e teto. Não poderá cumprila sem assegurar a toda a população educação de qualidade e atenção à saúde.

Para atingir tais objetivos, esse Estado precisa estar presente em todo o território nacional; dispor de instituições aparelhadas para orientar o desenvolvimento econômico e regular o mercado no espaço econômico nacional; 
assegurar o pleno exercício da cidadania democrática a todos os habitantes; proporcionar os serviços públicos básicos; estar preparado militarmente para defender com eficácia a integridade do território e a soberania nacionais.

\section{Conclusão}

A consciência de que a sociedade brasileira vive um dilema obviamente não permite antever cenários róseos para os próximos anos. Nem por isso, justifica-se uma atitude de desânimo ou desespero. Novamente a história nos põe diante de uma decisão crucial. Este é um dado positivo, pois, se as forças populares conseguirem vencer os desafios com os quais se defrontam, os futuros habitantes do Brasil poderão viver em uma sociedade justa, bem mais democrática e bem mais agradável que a de hoje. Resta-nos, nestes tempos difíceis, a grandeza de lutar para atingir esse objetivo - uma empreitada que dará sentido à existência dos que nela se engajarem.

"Em meio milênio de história, partindo de uma constelação de feitorias, de populações indígenas desgarradas, de escravos transportados de outro continente, de aventureiros europeus e asiáticos em busca de um destino melhor, chegamos a um povo de extraordinária polivalência cultural, um país sem paralelo pela vastidão territorial e homogeneidade lingüística e religiosa. Mas nos falta a experiência das provas cruciais, como as que conheceram outros povos cuja sobrevivência chegou a estar ameaçada. E nos falta também um verdadeiro conhecimento de nossas possibilidades, e principalmente de nossas debilidades. Mas não ignoramos que o tempo histórico se acelera, e que a contagem desse tempo se faz contra nós. Trata-se de saber se temos um futuro como nação que conta na construção do devir humano. Ou se prevalecerão as forças que se empenham em interromper o nosso processo histórico de formação de um Estado-nação" (Furtado, 1992: 35).

Referências bibliográficas

FERNANDES, Florestan. A revolução burguesa. Zahar, 1976.

FURTADO, Celso. Brasil: A construção interrompida. Rio de Janeiro, Paz e Terra, 1992.

PRADO Jr., Caio. A revolução brasileira, $7^{\text {a }}$ ed. São Paulo, Brasiliense, 1987.

SAMPAIO Jr., Plinio. Os impasses da formação nacional. In: José Luiz Fiori (org.). Estados e moedas no desenvolvimento das nações, Coletânea. Rio de Janeiro, Vozes, 1999.

Plínio Arruda Sampaio, advogado, foi coordenador do Plano de Ação do Governo Carvalho Pinto. Dirige atualmente o jornal semanal Correio da Cidadania. 